\title{
Mutagenic Effect of Diethyl Sulphate (DES) on the Chromosomes of Silkworm Bombyx mori L(Lepidoptera: Bombycidae)
}

\author{
LOKESH. G.: ANANTHANARAYANA S.R \\ Silkworm physiology research laboratory, Dept. of Studies in sericulture, Bangalore University, Bangalore-560 056, India. \\ E-mail:drdgloki@yahoo.com
}

\begin{abstract}
The silkworms of $\mathrm{NB}_{4} \mathrm{D}_{2}$ variety were treated with chemical mutagen Diethyl sulphate (DES). The larvae were subjected to two methods of treatments i.e., oral administration of the chemical mutagen and by injection of $8 \mathrm{mM}$ and $10 \mathrm{mM}$ concentrations of chemical mutagen through body wall. The lethal effect of the mutagen was studied in the subsequent generation. The effect was drastic on structure \& morphology of the meiotic chromosomes. Many structural, physiological and numerical aberrations were observed and documented. Certain numerical changes such as induction of polyploids were attributed to the improvements observed in the expression of commercial characters in the silkworm. @ JASEM
\end{abstract}

Silkworm is an ideal tool for conducting extensive basic scientific investigations because of its ease in handling, short life cycle and high fecundity (Tanaka, 1953). Extensive research work has been carried out by many scientists in the field of genetics, breeding, physiology, endocrinology, nutrition, and biochemistry of Bombyx mori L. (Tazima, 1978). Further, studies on radiation and chemical mutagenesis have been carried out to evolve superior silkworm breeds by utilizing the expression of their hereditary traits. However, several attempts have been made to induce beneficial mutations in the silkworm and some have proved to be useful to the sericultural industry (Narayanaswamy, et al, 1990). The developmental stages of the silkworm are under the constant interaction of genes. Each and every quantitative character of the silkworm is influenced/modified by the interaction of both genes and environment because of polygenic inheritance.Chemical mutagenesis has gained importance during the later period in genetic studies and mutation breeding. The chemical mutagens have advantages of higher efficiency and relatively greater specificity of mutation. Easy handling and availability of chemicals are additional benefits for mutation research (Chaturvedi, 1981). The majority of chemical mutagens induce aberrations and they are of the chromatid type, but chromosome-type aberrations also occur. An increase in polyploidy may indicate that a chemical has the potential to induce numerical aberrations. However, this method is not designed to measure numerical aberrations and is not regularly used for that purpose (Tazima, 1978).In silkworm Bombyx mori it is interesting to note that chromosomes are smallest cytologically, as inferred from the examination of trisomics, translocations and other aberrations, but inspite of this, its chromosome map is longest (Kawaguchi, 1928 and 1936). The incidence of visible chromosomal aberrations such as fragmentation, translocation, stickiness, ring formation, clumping etc. during spermatogenesis and oogenesis of the silkworm due to the mutagenic effect of chemicals were reported (Tazima et al., 1968; Datta et al., 1978; Sinha et al., 1993). Diethyl sulfate (DES) is reported to be a monofunctional and, strong alkylating agent. The studies on its mutagenicity were tested in many organisms including mice and Drosophila (Plecanos and Alderson, 1964). The cytological damage caused by this chemical is conspicuous in Drosophila when treated to males resulting in embryonic death. The chromosome breaks may be the causative factor for the dominant lethality and due to possibility of occurrence of point mutations owing to high toxicity of DES in adult flies. The potential breaks can undergo DNA replication and cell divisions as such and become open in different cell cycles resulting in impaired embryonic and post-embryonic developments. The visible chromosome aberrations like translocation, deletion etc. is reported to be caused by the action of DES in Drosophila (Munoz and Mazar Barnett, 1977).

The cytological study of mutagenic effect of chemical mutagens may be a useful tool in exploring the genetic variations, which might be induced by these mutagens for quantitative characters in silkworms. Since, many useful literatures are available pertaining to the action of chemical mutagens in different organisms, very little information is available regarding the effect of these mutagens in silkworms. Also information regarding the effect of DES on the cytological aspects of silkworms is scanty. So, an attempt was made in the present investigation to study the action of DES on the chromosomal environment of the silkworm Bombyx mori.

\section{MATERIALS \& METHODS}

The healthy larvae soon after the third moult considered for the experiment. Different concentrations (doses) of DES (Diethyl sulphate) viz., $2 \mathrm{mM}, 4 \mathrm{mM}, 6 \mathrm{mM}, 8 \mathrm{mM}, 10 \mathrm{mM}$ and $12 \mathrm{mM}$ 
were prepared in distilled water and orally administered through mulberry leaves. For every $20 \mathrm{~g}$ of leaves $20 \mathrm{ml}$ of appropriately diluted DES were used. Similarly, the injections for $5^{\text {th }}$ day of $\mathrm{V}^{\text {th }}$ instar larvae of bivoltine (variety: $\mathrm{NB}_{4} \mathrm{D}_{2}$ ) using different doses as mentioned earlier. The dilutions were prepared in $0.75 \%$ sodium chloride solution and injected at the lateral side of the intersegmental region between the $7^{\text {th }}$ and $8^{\text {th }}$ abdominal segments using a micro syringe. Each larva was injected with $0.04 \mathrm{ml}$ of solution. These treated larvae were maintained and observed upto spinning to find out the $\mathrm{LD}_{50}$ value in the larval life following the method of Bhoopathy and Muthukrishnan (1985). Further, after assessing the $\mathrm{LD}_{50}$ value, two different doses of DES namely $8 \mathrm{mM}$ and $10 \mathrm{mM}$ were selected. In the $\mathrm{M}_{1}$ generation, the larvae of treated and untreated batches from III instar upto late $\mathrm{V}$ instar were selected. The method used for cytological preparation was a modification of the conventional air drying technique of Premila Chanu et al., (1988) and Lakshmikumari et. al. (1996). The slides (prepared from treated and untreated material) were screened for different stages of meiotic chromosomes. The chromosomal morphology was studied to find out the chromosomal aberrations, if any. All lightmicrophotography was done with LEITZ (model: WILD) photomicroscope equipped with $35 \mathrm{~mm}$ camera. Photography was done on $35 \mathrm{~mm}$ Nova 125 ASA film (Black and White). The magnification used was $100 x$. The negatives were processed in a small daylight developing tank, following the conventional photographic techniques. The positive prints were made on sterling-kodabromide printing paper (hard glossy) and analysed for cytological abnormalities.A few treated \& untreated (control) larvae were allowed to spin the cocoons and were utilized for the study of commercial characters following the method described by Sonwalker (1991).

\section{RESULTS}

The various chromosomal aberrations induced by the chemical mutagen DES, an alkylating agent in the silkworm B.mori was well pronounced in the present observations. The aberrations noticed were of gross as well as individualistic type. The gross type aberrations included were of stickiness, clumping, pulverization, laggards etc. The individualistic type represents the so called point mutation including fragmentation, translocation and ring type chromosomes. The chemical mutagen DES on topical application treated at lower concentrations $(<8 \mathrm{mM})$ induced less chromosomal abnormalities or aberrations. But, higher concentrations of $10 \mathrm{mM}$ DES induced both physiological and structural chromosomal effects in meiotic spermatogonial cells (Figures: 1-11). However, the effect was meagre in oogonial cells. The commercial characters studied, shared a marked improvement in the shell ratio and filament length among the treated groups when compared with the control (Table 1).

* Corresponding author: Lokesh. G. 


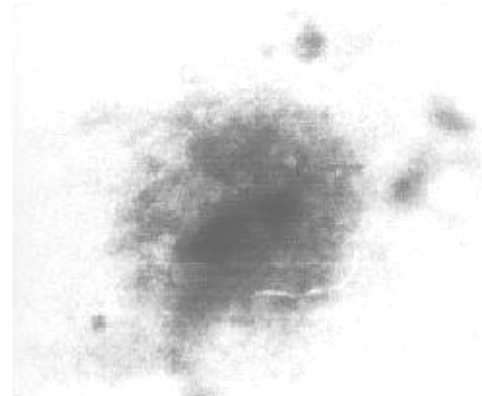

Fig-1: Inter Phase with distortion of nucleous

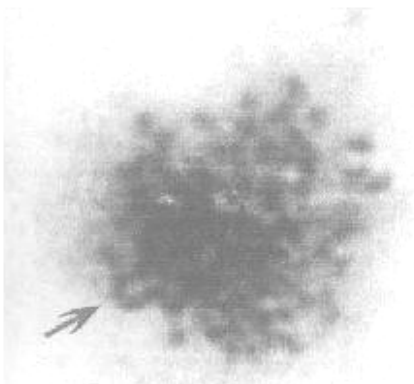

Fig-4: Metaphase II - Heteromorphic Quadravalent

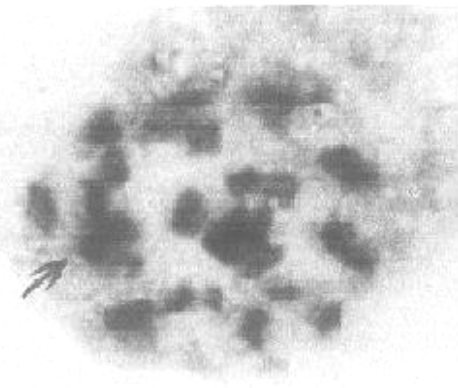

Fig-2: Diakinesis with heteromophic Bivalent

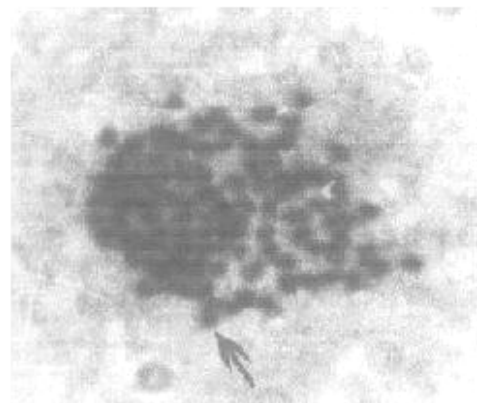

Fig-5: Metaphase II - Aberrent Chromosome

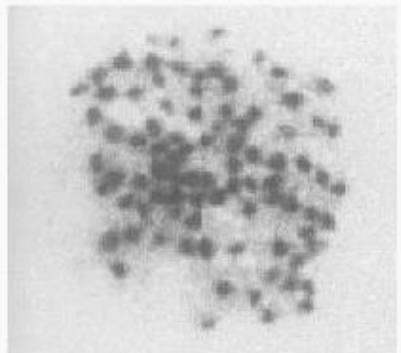

Fig-8: Triploid Chromosomes

Fig-7: Tetraploid Chromosomes

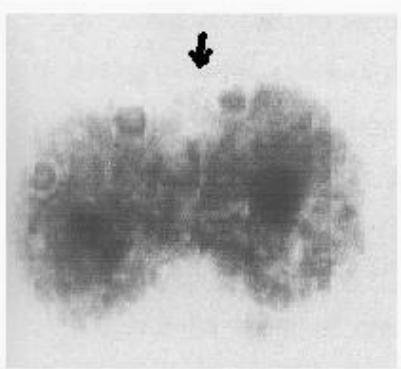

Fig-10

Fig-10 \& 11: Inter Cellular Chromosomal bridges

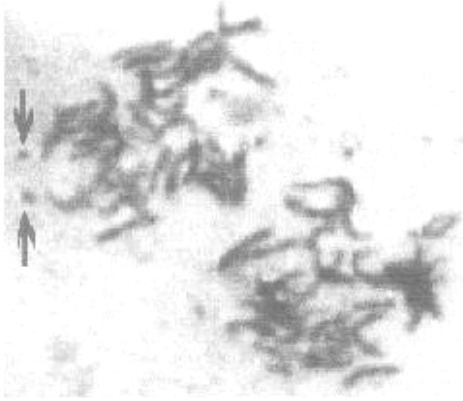

Fig-3: Pachytene Chromosomes with minute fragments

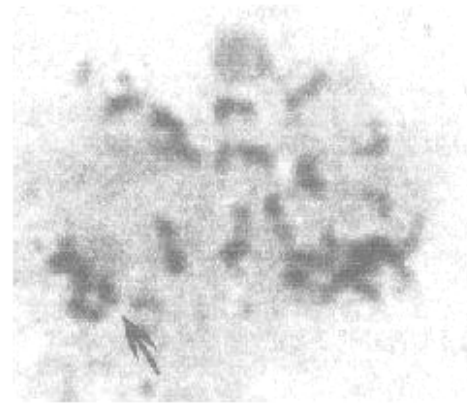

Fig-6: Metaphase I - Translocated Chromosome

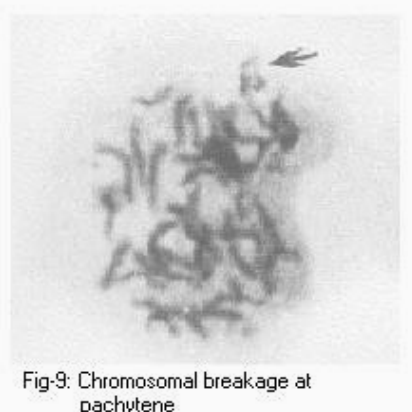

pachytene

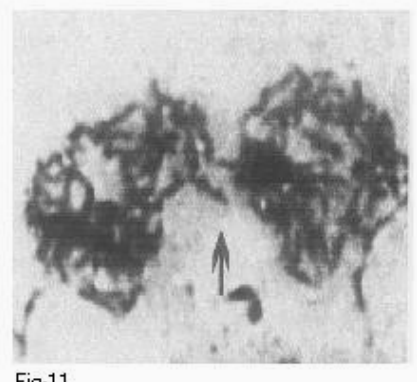

Fig-11

Figure. 1- 11: Different Types of Chromosomal Aberrations

* Corresponding author: Lokesh. G. 
TABLE-1: Mutagenic Effect of DES on Some of the Commercial Parameters

\begin{tabular}{ccll}
\hline & $\begin{array}{l}\text { Cocoon } \\
\text { Weight } \\
(\mathrm{gms})\end{array}$ & $\begin{array}{l}\text { Shell } \\
\text { ratio(\%) }\end{array}$ & $\begin{array}{l}\text { Filament } \\
\text { length }(\mathrm{mts})\end{array}$ \\
\hline DES Treated & 1.91 & 19.375 & 1010.74 \\
$(8 \mathrm{mM})$ & $\pm 0.16^{*}$ & $\pm 0.97^{*}$ & $\pm 18.014^{*}$ \\
DES Treated & 1.823 & 17.30 & 863.25 \\
$(10 \mathrm{mM})$ & $\pm 0.087^{*}$ & $\pm 0.080^{*}$ & $\pm 25.47^{*}$ \\
\hline Control & 1.72 & 18.60 & 895.50 \\
& $\pm 0.055^{*}$ & $\pm 0.75^{*}$ & $\pm 59.507^{*}$ \\
\hline
\end{tabular}

* Standard deviation

\section{DISCUSSION}

The physiological aberrations caused by the DES in the present study, such as chromosome stickiness and clumping at different meiotic stages were attributed to the depolymerisation and cross linking of DNA of the chromosome. This is in agreement with the earlier works of Darlington (1942), Evans (1962) in Drosophila, Rai (1964) in Aedes aegypti mosquitoes and Lakshmikumari (1995) in B.mori. According to Sturelid (1971) most of the physiological chromosomal aberrations appear due to the damage caused during replication of DNA by alkylation. The chromosomal bridges with fragments, single bridge, dicentric bridges observed were probably due to the chromosomal stickiness at earlier stages. The production of dicentric bridges was mainly due to the spontaneous breakage of meiotic chromosome (Lewis and John, 1966).

From the present study, it is realized that the DES, an alkylating chemical mutagen, is capable of inducing chromosomal aberrations effectively on the germ cells of the silkworm B.mori, as it was evident from earlier reports that, this chemical extensively produce chromosomal aberrations in Drosophila (Alderson and Pelecanos, 1964; Munoz and Barnette, 1978). The limited chromosomal aberrations induced by DES in the present investigation could be attributed to the fact that ionizing radiations induce mutations in germ cells belonging to all the stages of the gametogenic cycle, thought with markedly different rates. On the contrary, chemical mutagens induce mutations only in certain spermatogenic stages. The stage specific induction of mutation by chemical agents is very likely due to their different pathways and their varied effects on the structure and various macromolecular processes during the development of the germ cells (Sinha et al., 1993). Thus the present investigation highlights the effect of chemical mutagen (DES) in the induction of chromosomal aberrations leading to polyploidy which will have a direct effect on the expression of commercial characters in silkworm.

\section{REFERENCES}

Agarwal, V. P. and Sastry, K. V. (1976). In ; A Text book of Genetics. Published by K.Nath \& Co. Meerut.

Alderson, T., and Pelecanos, M. (1964). The mutagenic activity of diethyl sulphate in Drosophila melanogastor, II. The sensitivity of the immature (larval) and adult testis, Mutation Research, 1; 182-192.

Auerbach, C. and Robson, J.M. (1946); Chemical production of mutations. Nature, 157: 302.

Auerbach, C. (1976). Mutation research problems, results and perspectives. John Wiley and Sons, Inc., New York, : 256-353.

Bauer, M. (1967). Die kinetische organization der lepidopteren-Chromosomen. Chromosoma, 22 : 101-125.

Bhoopathy, R. and Muthukrishnan, Y. S. (1985); Mutagenic effect of Diethyl sulfate (DES) on mulberry silkworm Bombyx mori.L., Ind. J. Seric., 24(1): 25-32.

Browning, L. S. (1969) Mutational spectrum produced in Drosophila by N-methyl-N-nitro-Nnitrosoguanidine. Mutation Res., 56 : 299-304.

Chaturvedi (1981). The chemical and physical mutations In : the text book of genetics. IBH publication, New Delhi.

Darlington, C. D. (1942). Chromosome chemistry and gene action. Nature, $149: 66-69$.

Darlington, C. D. and Lacour, L. F. (1945). Chromosome breakage and the nucleic acid cycle (Trillium, Traderscantia, Vicia)., J. Genet. $46: 180-267$.

Datta, R. K., Sengupta, K. and Das, S. K. (1978 a). Sensitivityof male germ cells in silkworm to EMS. Mutat. Res. 51 : 199-304.

Datta, R. K., Sengupta, K. and Das, S. K. (1978 b). Induction of dominant lethals with ethyl methane sulfonate in male germ cells of mulberry silkworm,

Day, M.F. and Waterhouse, D.F. (1953). The mechanism of digestion. In : "Insect physiology". (Ed. By Roeder K D) pp. 311-330, Wiley, New York: Chapman \& Hall, London.

* Corresponding author: Lokesh. G. 
Deokar, G. B. and Thakar, C. V. (1958). Cytogenetical studies in Indian silkworm Attacus ricini. Curr. Sci., 11: 457.

Deokar, G. B., Chowdhur, S. N., Bhuyan, B. N. and Kshirsagar, K. K. (1962). Cytogenetic studies in Indian silkworms. Current Sci., $27: 457$.

Evans, A. C. (1939). The utilization of food by certain Lepidopteran larvae. Trans. R. Ent. Soc. London., 89:13-22.

Gamo, T. (1983). Biochemical genetics and its application to the breeding of silkworms. JARQ. 16(4): 264-272.

Generoso, W. M., Russell, W. L., Sandra, W. H., Sandra, K. S. and Gosslee, D. G. (1974). Effects of dose on the induction of dominant lethal mutations and heritable translocations with Ethyl methane sulfonate in male mice, Genetics., 77 : 741-752.

Inagaki,E and Oster,I.I. (1969); Changes in the mutational response of silkworm spermatozoa exposed to mono and polyfunctional alkylating agents following storage, mutation Res., 7: 425432.

Kawaguchi, E. (1928). Zytologische unterscuhungen an Seiden spinner and seinen Verwanten I. Gametogenesis von Bombyx mori L. and Bombyx mandarina. M. Land ihrer bastarde. $\mathrm{Z}$. Zelforsch., 7: 519-552.

Kawaguchi, E. (1936). Der Eingluss der Eierbenhandlung mit Zebtrifugierung auf die vererbung bei dem seiden spinner. I. Uber experimentalle Auslosung der polyploiden Mutation. J. Fac. Ar. Hokkaido. Imp. Uni., 38 : 111-133.

Kawaguchi, E. and Yoshida, T. H. (1953). Cytological studies on the inter racial hybrids of Samia cynthia ricini (Lepidoptera ; Saturnidae), La Kromosoma, 657 : 17-19.

Kawamura, N. (1978). The early embryonic mitosis in normal and cooled eggs of the silkworm, Bombyx mori. J. Morph, $158: 57-71$.

Kawamura, N. (1981). Induction of hexaploid and octaploid specimens in the silkworms (Bombyx mori) by exposing to low temperature. Proc. Jap. Acad. Ser B., 57 (3) : 77-82.
Kerimova, I. O. (1978). Mutagenic effect of Dimethyl sulfate and N-Nitrosoethyl urea on Bombyx mori, Genetika., 14 : 63-67.

King, R. C. and Akai, H. (1971 b). Spermatogenesis in Bombyx mori. II. The ultrastructure of synapsed bivalents. J. Morph, 134 : 181-194.

Lakshmikumari,B., Jayaprakash and Ananthanarayana, S.R. (1994). A rapid technique for obtaining air dried mitotic chromosomes from the eggs of silkworm. Sericologia, 34(1) : 89-93.

Lakshmikumari, B., Jayaprakash and Ananthanarayana, S.R. (1996). Effect of gamma radiation on meiotic chromosomes of Bombyx mori. L., J. Cytol. Genet., 31(3) : 27-30.

Legay, J.M. (1961 a). Etude de la stabilite d'une correlation enter deux character quantitatifs. Ann. Epiphytics, 12(4) : 381-391.

Legay, J.M. (1961 b). Problems poses par l'estimation de l' heritabilite de quelques caracteres quantitatifs chez Bombyx mori. Annales de genetique, 4(2): 67-72.

Lewis, K. R. and John, B. (1966). The meiotic consequence of spontaneous chromosome breakage. Chromosoma, $18: 287$.

Munoz, E. R. and Mazar Barnett, B. (1977). II-III translocations induced by diethyl sulphate in mature sperm of Drosophila melanogaster, Mutation Research, 45; 355-357.

Munoz, E. R. and Mazar Barnett, B. (1978). Embryonic and post-embryonic lethals induced by diethyl sulfate in mature sperm of Drosophila melanogastor, Mutation Research, 51; 37-44.

Murakami, A. and Imai, H. T. (1973). Studies on chromosomes of the silkworm. Bombyx mori. Ann. Rept. Natl. Inst. Genet. (Japan), 23 : 54-56.

Narayanaswamy, K.C., Govindan, R. and Narayanaswamy,T.K.(1990). Physical mutagens and their effects on silkworms. Indian silk, May 1990, 39- 41.

Pelecanos, M. and Alderson, T. (1964). The mutagenic activity of diethyl sulphate in Drosophila melanogaster. The dose-mutagenic response to larval and adult feeding, Mutation Research, 1; 173-181. 
Pelecanos, M. and Alderson, T. (1964). The mutagenic activity of diethyl sulphate in Drosophila melanogaster, III. The sensitivity of the immature (larval) and adult ovary, Mutation Research, 1; 302-309.

Premila Chanu, O. Ibotombi, N. Kundu, S. C. and Bhagirath, T. (1988). The course of meiosis in Indian female eri silkworm. Samia cynthia ricini. Sericologia, 28(1) : 39-44.

Rai, K. S. (1964). Cytogenetic effects of chemosterilants in mosquitoes I. Apholateinduced abrrations in the somatic chromosomes of Aedes aegypti L., Cytologia, 29 : 346-353.

Sinha, R. K., Srivastava, P. K. and Sinha, S. P. (1993). Effect of mutagens on the structure and movement of chromosomes in the primary spermatocytes of silkworm Bombyx mori L. National Conference on Mulberry Sericulture Research, Bhagalpur, India.
Sonwalker, T. N. (1991). Handbook of silk technology. Wiley Eastern Ltd., New Delhi. 462.

Sturelid (1971). Chromosome breaking capacity of tepa and analogues in Vicia faba and Chinese hamster cells. Hereditas., 68 : 255-275.

Tanaka, Y. (1953); Genetics of the silkworm Bombyx mori. L., Adv. In Genetics, 5: 239-301.

Tazima, Y. (1978 a). Radiation mutagenesis of the silkworm. In : "The silkworm : an important laboratory tool”. (Ed. By Tazima Y), Kodansha Ltd., Tokyo, 213-245.

Tazima,Y and Onimaru,K (1968); Mutagenic action of Mytimyci-C and EMS on pre-meiotic cells of male silkworms. Ann. Rep. Natt. Inst. Genet. (Japan), 19: 62-63.

* Corresponding author: Lokesh. G. 